\title{
Effects of Ammonia on Freshwater Mussels in the St. Croix River
}

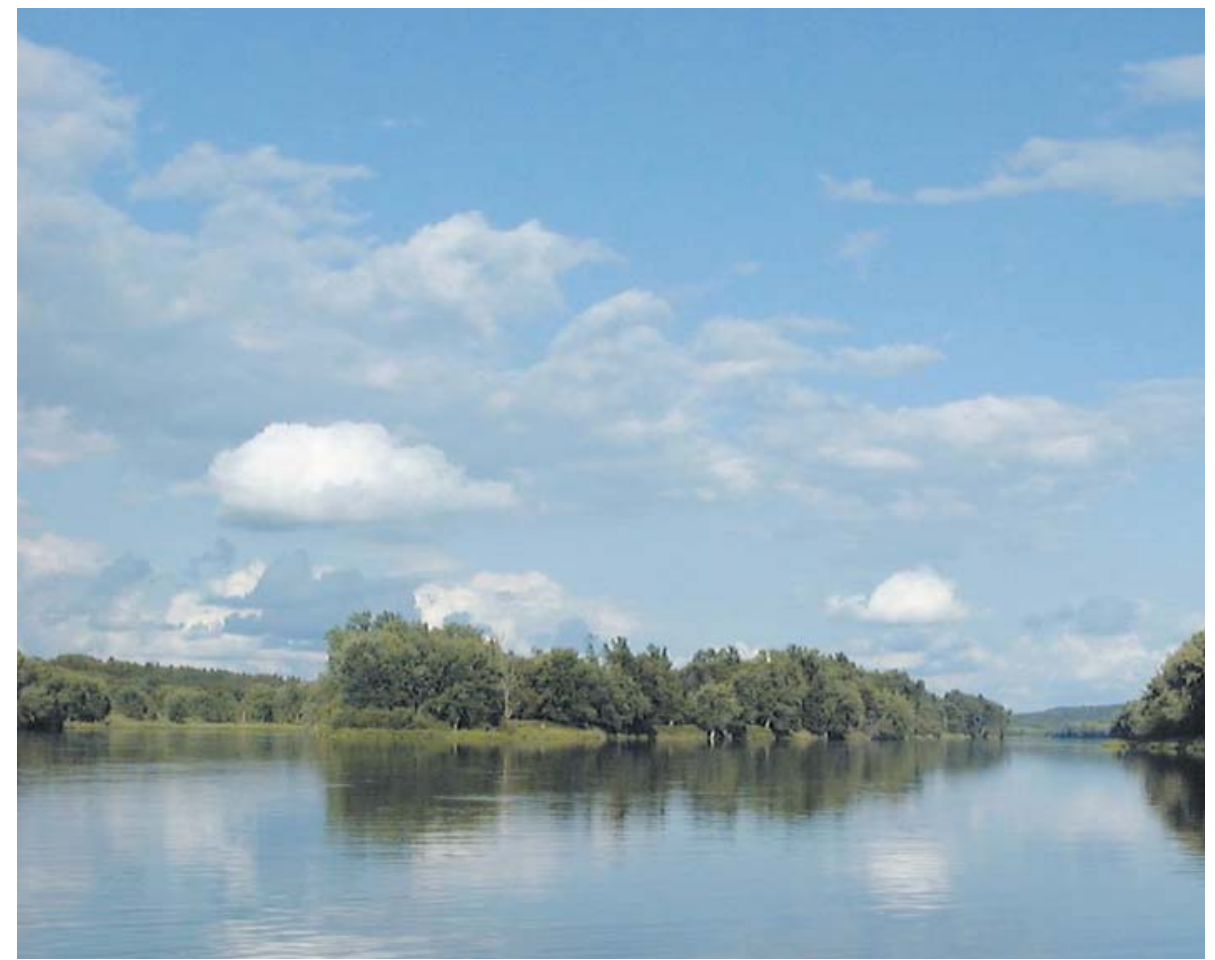

St. Croix River

Freshwater mussels, animals sensitive to changes in habitat quality, are the largest group of endangered animals in North America. Freshwater mussels are a renewable resource that provides significant economic and environmental benefits to the Nation. Their shells are used in the cultured pearl industry; they are a food resource for many animals; and they filter contaminants, sediment, and nutrients from water, thereby improving water quality. Scientists see the mussels' demise as a serious warning for lakes, rivers, and streams. When mussels begin to disappear, it is a sign that other species, and even whole ecosystems, may also be in jeopardy.

\section{...un-ionized ammonia $\left(\mathrm{NH}_{3}\right)$ is particularly toxic to aquatic animals...}

The St. Croix River basin (30 km east of Minneapolis-St. Paul, Minnesota) is experiencing rapid land-use changes-from forest and agriculture to suburbanization - as the metropolis of Minneapolis-St. Paul sprawls into the surrounding countryside.
The National Park Service, which administers most of the St. Croix, is concerned that urbanization will also increase the output of nutrient-rich effluent from wastewater treatment plants into the river. This may result in an elevation of ammonia in river sediments. Ammonia is a common pollutant that enters rivers primarily from sewage discharge, fertilizers, and natural processes mediated by river bacteria. However, the un-ionized form of ammonia $\left(\mathrm{NH}_{3}\right)$ is particularly toxic to aquatic animals.

The St. Croix River contains a diverse and abundant group of freshwater mussels. The St. Croix is one of the few rivers in the Midwest not substantially affected by the invasion of the exotic zebra mussel, which encrusts and kills native freshwater mussels. Increased concentrations of ammonia in river sediments, however, poses a significant threat to mussels.

The Upper Midwest Environmental Sciences Center has completed a 3-year study that examined the effects of ammonia on native mussels. We used native mussels because they are considered one of the most important natural resources in the St. Croix River and they are very sensitive to ammonia.

In a series of laboratory studies, juvenile pocketbook mussels (Lampsilis cardium) were exposed to a range of ammonia

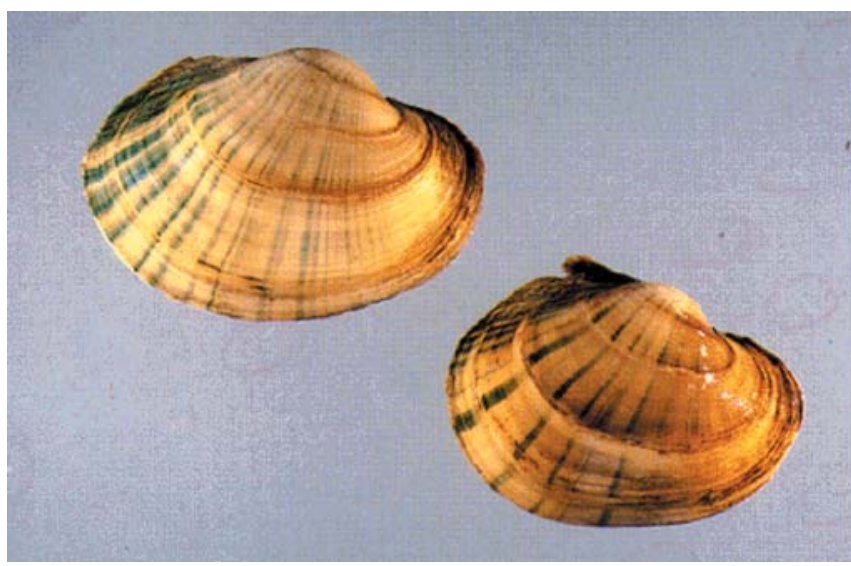

Pocketbook mussels

(Lampsilis cardium)
Photo by Kevin Cummings Used by permission 


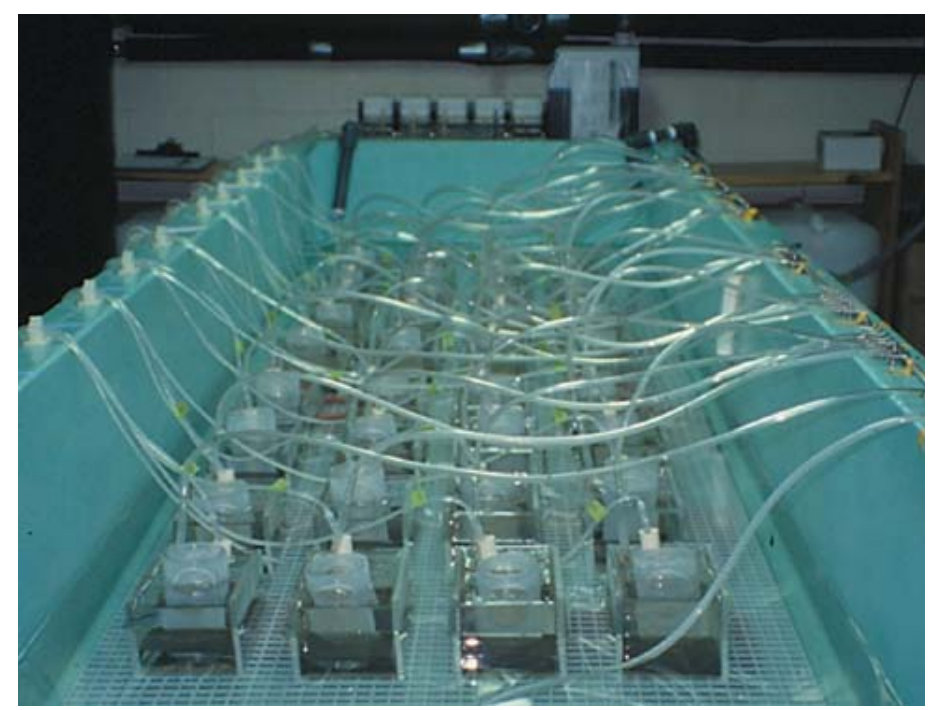

Laboratory setup

concentrations delivered into river sediments. We exposed mussels to ammonia for 4 and 10 days and then measured the concentration of ammonia that killed or reduced the growth of mussels. Concentrations as low as $127 \mu \mathrm{g} \mathrm{NH} / \mathrm{L}$ were lethal to $50 \%$ of the mussels after 4 days; concentrations as low as $93 \mu \mathrm{g}$ $\mathrm{NH}_{3} / \mathrm{L}$ killed $50 \%$ of the mussels after 10 days. The growth rate of mussels was substantially reduced at ammonia concentrations as low as $31 \mu \mathrm{g} \mathrm{NH}_{3} / \mathrm{L}$. These concentrations are lower than the existing national water quality criteria, suggesting that these criteria may not be protecting juvenile mussels.

In a companion field study, we placed juvenile pocketbook mussels into small chambers that were placed into river sediment at eight locations throughout the river. After 4, 10, and 28 days, we retrieved the chambers and measured the survival

\section{Elevated concentrations of ammonia in river sediments pose a significant threat to mussels.}

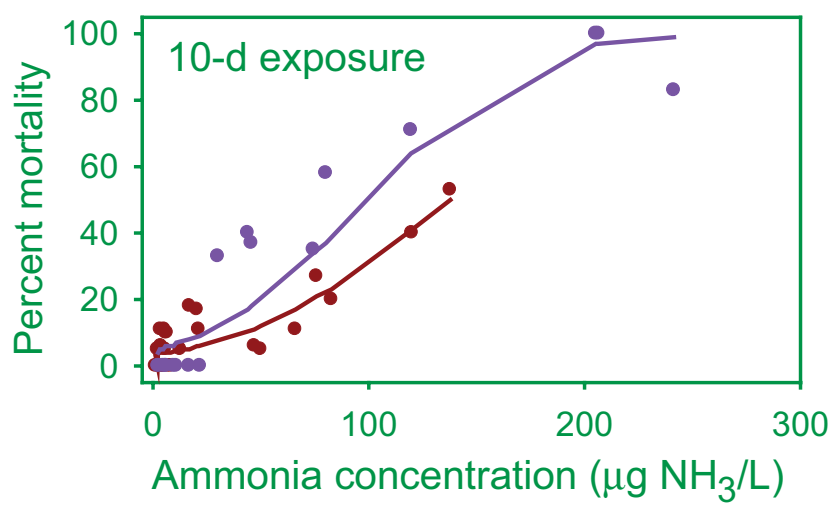

Laboratory mortality and growth of the mussels. Ammonia concentrations in river sediments ranged from 0.1 to $107 \mu \mathrm{g} \mathrm{NH}_{3} / \mathrm{L}$ and were highly variable within a location. Survival and growth of mussels were also highly variable and were generally unrelated to ammonia concentrations. The large variability in the field measures made it difficult to observe a relation between ammonia and survival or growth of

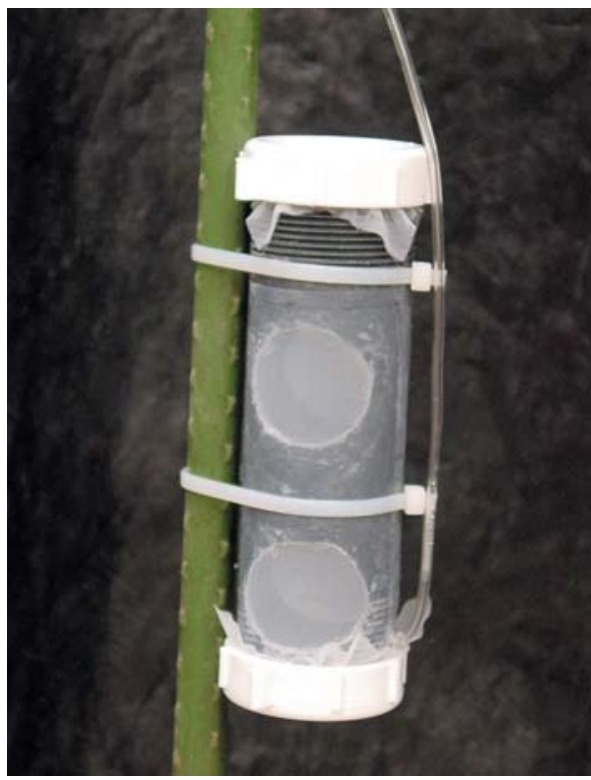
Mussel chamber mussels.

Although freshwater mussels are frequently used as indicators of contaminant exposure, the large variance associated with measuring survival and growth of juveniles in the field suggests that more sensitive effects-level endpoints need to be found in this imperiled faunal group. Laboratory experiments, conducted under highly controlled conditions, suggest that $\mathrm{NH}_{3}$ is quite toxic to juveniles at concentrations that are occasionally exceeded in the St. Croix River. In the river, however, sediments may not be consistently toxic; rather, periods of episodic toxicity may occur when certain conditions (high temperature and low flow) are present.

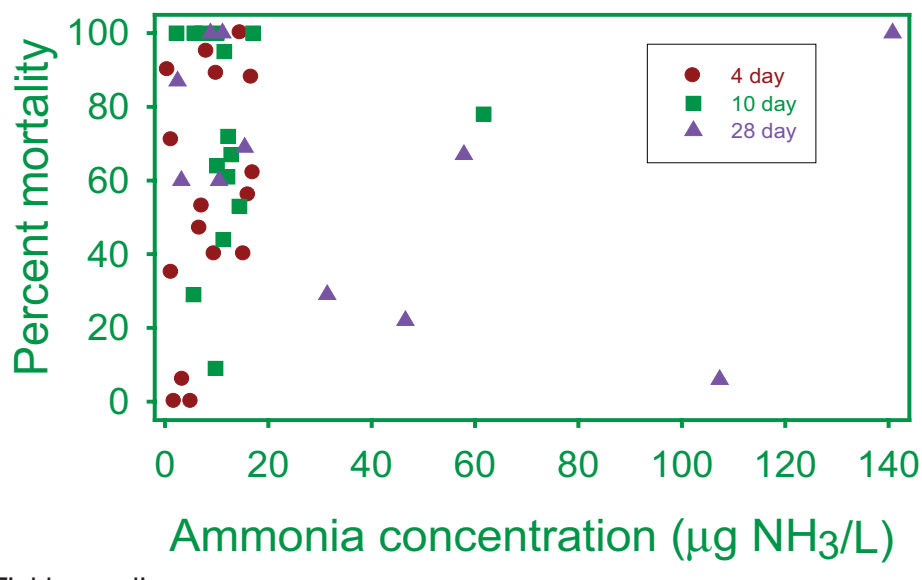

Field mortality

\section{For more information, contact}

Teresa Newton USGS Upper Midwest Environmental Sciences Center 2630 Fanta Reed Road

La Crosse, Wisconsin 54603

Phone: 608.781.6217

Email: tnewton@usgs.gov 